\title{
A Study on the Regeneration Performance Characteristics of an Internally Heated Regenerator in a Liquid Desiccant System
}

\author{
Ji-Hyun Mun ${ }^{1}$, Dong-Soon Jeon ${ }^{2}$, Seon-Chang $\mathrm{Kim}^{2}$ and Young-Lyoul Kim² \\ ${ }^{1}$ Energy System Engineering \\ Korea University of Science and Technology \\ PO BOX 305-350 Deajeon (Republic of Korea) \\ Phone/Fax number: +82 41589 8346/+82 41589 8330, e-mail: bugiruni@kitech.re.kr \\ ${ }^{2}$ Thermal \& Fluid System R\&BD Group \\ Korea Institute of Industrial Technology \\ PO BOX 331-822 Cheonan (Republic of Korea) \\ Phone/Fax number: +82 41589 8329/+82 41589 8330, e-mail: geengeen@kitech.re.kr, kimsc@kitech.re.kr, \\ r6058@kitech.re.kr
}

\begin{abstract}
This paper presents a study of the regeneration performance characteristics of an internally heated regenerator applicable to a liquid desiccant system. The internally heated regenerator used in this study was designed and manufactured to provide good regeneration performance. An experimental setup was established to test the regeneration performance. $\mathrm{LiCl}$ aqueous solution was used as working fluid. Variables to evaluate regeneration performance characteristics of the internally heated regenerator were dry bulb temperature, relative humidity and velocity of regeneration air, mass flow rate, temperature and concentration of the $\mathrm{LiCl}$ aqueous solution. The experimental conditions were chosen by using a $1 / 2$ fractional factorial DOE. Regeneration rate and regeneration effectiveness were taken as results. From the results, solution concentration and regeneration air relative humidity have strong effects on the regeneration rate. The regeneration effectiveness was affected mostly by regeneration air velocity and $\mathrm{LiCl}$ aqueous solution temperature.
\end{abstract}

\section{Key words}

Internally heated regenerator, $\mathrm{LiCl}$ aqueous solution, Fractional factorial DOE, Regeneration rate, Regeneration effectiveness.

\section{Introduction}

Liquid desiccant systems can effectively control the latent heat load in moist air and enable the use of low grade energy such as solar heat and waste heat to regenerate the solution. Compared with existing air conditioning systems, liquid desiccant system can reduce energy consumption and thus can be described as eco-friendly. It is important to enhance heat and mass transfer performance in dehumidifying and regenerating process because dehumidifier plays a major role in desiccant system performance and regenerator consumes most energy of liquid desiccant system. Against the backdrop, many studies [1]-[4] are being conducted on various types of internally cooled/heated dehumidifiers and regenerators. Recently, Yin et al. [1]-[2] carried out experiments and an analysis on the performance of an internally cooled/heated dehumidifier/regenerator, and compared the results with the performance of a packed bed type dehumidifier/ regenerator. Zhang et al. [3] presented the results of the experiments and numerical analysis for dehumidification characteristics of an internally cooled dehumidifier. Luo et al. [4] developed a new performance predication model using CFD, and analyzed heat and mass transfer characteristics of liquid desiccant dehumidifier under various simulation conditions. Since differences in heat and mass transfer characteristics exist with regenerator type and the flow directions of the fluids (liquid desiccant, heating water and regeneration air), it is essential to study the characteristics of regeneration performance of the proposed regenerator.

Experiments were conducted to examine regeneration performance, and the variables were dry bulb temperature, relative humidity and velocity of regeneration air, temperature, concentration and mass flow rate of the solution. $\mathrm{LiCl}$ aqueous solution was used as working fluid. Experimental conditions were chosen using a $1 / 2$ fractional factorial DOE, and the effects of experimental variables on regeneration performance were analyzed.

\section{Internally heated regenerator}

Fig. 1 is a schematic diagram of the internally heated regenerator manufactured in this study. The internally heated regenerator consists of the five plates and an upper/lower header for heating water and $\mathrm{LiCl}$ aqueous solution. Including the headers, the regenerator measures $88 \mathrm{~mm}$ in length, $243 \mathrm{~mm}$ in width, and $695 \mathrm{~mm}$ in 
height. It was made of an ABS (XR-474) resin in consideration of the corrosiveness of the $\mathrm{LiCl}$ aqueous solution. The plate got grooved surface to enhance flowability and was coated with a hydrophilic liquid to improve wettability on the surface. Regeneration air is in cross flow with the $\mathrm{LiCl}$ aqueous solution at the plate surface, while the heating water is in counter flow with the $\mathrm{LiCl}$ aqueous solution. The heating water sustains a high vapor pressure difference between the regeneration air and the $\mathrm{LiCl}$ aqueous solution by maintaining high temperature of the $\mathrm{LiCl}$ aqueous solution during the regeneration process.

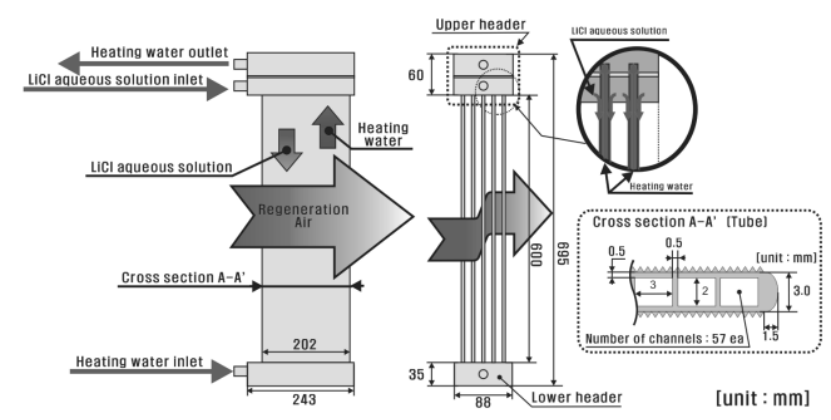

Fig. 1. Internally heated regenerator.

\section{Experiment}

\section{A. Setup and method}

The experimental setup was built to examine the regeneration performance characteristics of the internally heated regenerator. As shown in Fig. 2, the experimental setup consists of a $\mathrm{LiCl}$ aqueous solution supply unit, test section, regeneration air circulation unit and heating water circulation unit. Concentrations of $\mathrm{LiCl}$ aqueous solution at the inlet and outlet of the test section were calculated by the temperature (measured by temperature sensor RTD) and density (measured by sampling) of the $\mathrm{LiCl}$ aqueous solution. Measurements were taken twice, at the beginning and end of each experiment, in a steady state.

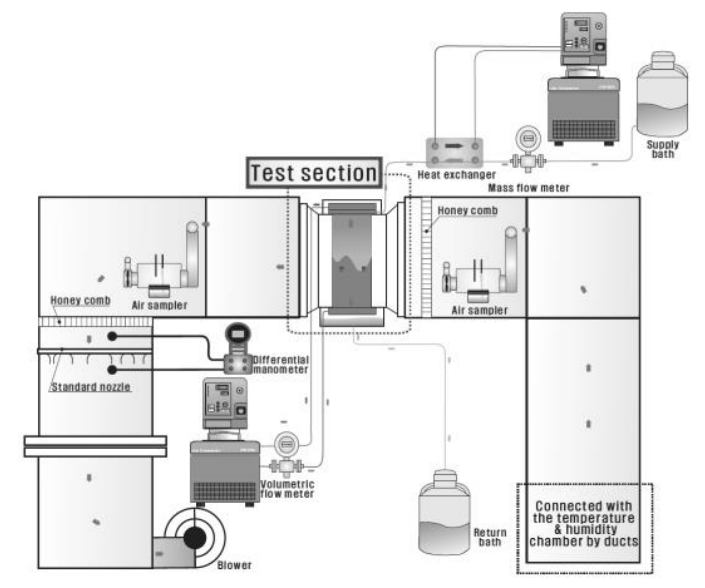

Fig. 2. Schematic diagram of experimental setup.

\section{B. Experimental conditions}

For investigating the regeneration performance characteristics of the internally heated regenerator, the selected experimental variables were dry bulb temperature, relative humidity and velocity of regeneration air, temperature, concentration and mass flow rate of the $\mathrm{LiCl}$ aqueous solution. Table 1 shows the experimental variables and their values. Experimental conditions were chosen using a $1 / 2$ fractional factorial DOE, and Table 2 presents the final $32\left(2^{6-1}\right)$ sets. The temperature and volumetric flow rate of the heating water were fixed at $80^{\circ} \mathrm{C}$ and $2.5 \ell / \mathrm{min}$, respectively.

Table 1. Experimental variables and values

\begin{tabular}{|c|c|c|}
\hline \multicolumn{2}{|c|}{ Experimental variables } & Values \\
\hline \multirow{2}{*}{$\begin{array}{c}\text { Regen- } \\
\text { eration } \\
\text { air }\end{array}$} & Dry bulb temperature, $T_{a, i}\left[{ }^{\circ} \mathrm{C}\right]$ & 30,35 \\
\cline { 2 - 3 } & Relative humidity, $R H_{i}[\%]$ & 30,60 \\
\cline { 2 - 3 }$\left[\begin{array}{c}\mathrm{LiCl} \\
\text { aqueous } \\
\text { solution }\end{array}\right.$ & Velocity, $V_{a, i}[\mathrm{~m} / \mathrm{s}]$ & $0.5,2.0$ \\
\cline { 2 - 3 } & Temperature, $T_{s, i}\left[{ }^{\circ} \mathrm{C}\right]$ & 60,70 \\
\cline { 2 - 3 } & Concentration, $C_{s, i}[\%]$ & 36,40 \\
\hline
\end{tabular}

Table 2 Experimental conditions of $1 / 2$ fractional factorial DOE and results

\begin{tabular}{|c|c|c|c|c|c|c|c|c|}
\hline \multirow{3}{*}{ No. } & \multicolumn{6}{|c|}{ Experimental conditions } & \multicolumn{2}{|c|}{ Results } \\
\hline & \multicolumn{3}{|c|}{ Regeneration air } & \multicolumn{3}{|c|}{$\begin{array}{l}\mathrm{LiCl} \text { aqueous } \\
\text { solution }\end{array}$} & \multirow{2}{*}{$\begin{array}{c}\dot{m}_{\text {reg, }, a} \\
{[\mathrm{~g} / \mathrm{min}]}\end{array}$} & \multirow{2}{*}{$\begin{array}{l}\boldsymbol{\varepsilon}_{\text {reg }} \\
{[\%]}\end{array}$} \\
\hline & $\begin{array}{r}T_{a, i} \\
{\left[{ }^{\circ} \mathrm{C}\right]}\end{array}$ & $\begin{array}{l}\mathrm{RH}_{i} \\
{[\%]}\end{array}$ & $\begin{array}{c}V_{a, i} \\
{[\mathrm{~m} / \mathrm{s}]}\end{array}$ & $\begin{array}{c}T_{s, i} \\
{\left[{ }^{[\mathrm{C}}\right]}\end{array}$ & $\begin{array}{r}C_{s, i} \\
{[\%]}\end{array}$ & $\begin{array}{l}\dot{m}_{s, i} \\
{[\mathrm{~g} / \mathrm{s}]}\end{array}$ & & \\
\hline 1 & 30 & 30 & 0.5 & 60 & 36 & 3 & 16.73 & 41.7 \\
\hline 2 & 35 & 30 & 0.5 & 60 & 36 & 9 & 21.03 & 58.6 \\
\hline 3 & 30 & 60 & 0.5 & 60 & 36 & 9 & 17.89 & 62.7 \\
\hline 4 & 35 & 60 & 0.5 & 60 & 36 & 3 & 15.2 & 71.9 \\
\hline 5 & 30 & 30 & 2.0 & 60 & 36 & 9 & 27.44 & 16.9 \\
\hline 6 & 35 & 30 & 2.0 & 60 & 36 & 3 & 23.81 & 16.2 \\
\hline 7 & 30 & 60 & 2.0 & 60 & 36 & 3 & 19.86 & 17.4 \\
\hline 8 & 35 & 60 & 2.0 & 60 & 36 & 9 & 21.63 & 25.5 \\
\hline 9 & 30 & 30 & 0.5 & 70 & 36 & 9 & 19.71 & 26.4 \\
\hline 10 & 35 & 30 & 0.5 & 70 & 36 & 3 & 18.71 & 26.6 \\
\hline 11 & 30 & 60 & 0.5 & 70 & 36 & 3 & 16.58 & 26.7 \\
\hline 12 & 35 & 60 & 0.5 & 70 & 36 & 9 & 18.2 & 33.7 \\
\hline 13 & 30 & 30 & 2.0 & 70 & 36 & 3 & 20.87 & 6.9 \\
\hline 14 & 35 & 30 & 2.0 & 70 & 36 & 9 & 29.71 & 10.5 \\
\hline 15 & 30 & 60 & 2.0 & 70 & 36 & 9 & 24.38 & 9.7 \\
\hline 16 & 35 & 60 & 2.0 & 70 & 36 & 3 & 17.42 & 7.9 \\
\hline 17 & 30 & 30 & 0.5 & 60 & 40 & 9 & 13.69 & 50.0 \\
\hline 18 & 35 & 30 & 0.5 & 60 & 40 & 3 & 16.73 & 71.2 \\
\hline 19 & 30 & 60 & 0.5 & 60 & 40 & 3 & 10.08 & 65.1 \\
\hline 20 & 35 & 60 & 0.5 & 60 & 40 & 9 & 11.7 & 135.4 \\
\hline 21 & 30 & 30 & 2.0 & 60 & 40 & 3 & 17.63 & 15.9 \\
\hline 22 & 35 & 30 & 2.0 & 60 & 40 & 9 & 26.71 & 28.4 \\
\hline 23 & 30 & 60 & 2.0 & 60 & 40 & 9 & 14.31 & 22.4 \\
\hline 24 & 35 & 60 & 2.0 & 60 & 40 & 3 & 12.15 & 35.8 \\
\hline 25 & 30 & 30 & 0.5 & 70 & 40 & 3 & 12.44 & 23.1 \\
\hline 26 & 35 & 30 & 0.5 & 70 & 40 & 9 & 19.43 & 39.3 \\
\hline 27 & 30 & 60 & 0.5 & 70 & 40 & 9 & 12.55 & 30.5 \\
\hline 28 & 35 & 60 & 0.5 & 70 & 40 & 3 & 11.28 & 33.9 \\
\hline 29 & 30 & 30 & 2.0 & 70 & 40 & 9 & 20.33 & 9.2 \\
\hline 30 & 35 & 30 & 2.0 & 70 & 40 & 3 & 24.16 & 11.9 \\
\hline 31 & 30 & 60 & 2.0 & 70 & 40 & 3 & 10.43 & 6.3 \\
\hline 32 & 35 & 60 & 2.0 & 70 & 40 & 9 & 14.61 & 10.7 \\
\hline
\end{tabular}




\section{Data reduction}

Equations (1) (9) are used to analyze the results of the regeneration performance characteristics in this paper. Equations (1) (2) are heat and mass balance equations. The heat transfer rates of heating water, $\mathrm{LiCl}$ aqueous solution, and regeneration air were respectively calculated from equations $(3) \sim(5)$. Also, equations $(6) \sim(7)$ give the regeneration rates of $\mathrm{LiCl}$ aqueous solution and regeneration air. Equation (8) provides the regeneration effectiveness. As shown in equation (9), the equilibrium humidity ratio $\left(\omega_{e q, i}\right)$ can be expressed as a function of the inlet temperature and concentration of the $\mathrm{LiCl}$ aqueous solution.

- Heat and mass balance

$$
\begin{aligned}
& Q_{w}=Q_{s}+Q_{a} \\
& \dot{m}_{\text {reg }, s}=\dot{m}_{\text {reg }, a}
\end{aligned}
$$

- Heat and mass transfer rate

$$
\begin{gathered}
Q_{w}=\dot{m}_{w} c_{p, w}\left(T_{w, i}-T_{w, o}\right) \\
Q_{s}=\dot{m}_{s, i} h_{s, i}-\dot{m}_{s, o} h_{s, o} \\
Q_{a}=\dot{m}_{d a}\left(h_{a, i}-h_{a, o}\right) \\
\dot{m}_{r e g, s}=\dot{m}_{s, i}-\dot{m}_{s, o} \\
\dot{m}_{r e g, a}=\dot{m}_{d a}\left(\omega_{a, o}-\omega_{a, i}\right)
\end{gathered}
$$

- Regeneration effectiveness

$$
\begin{array}{r}
\boldsymbol{\varepsilon}_{r e g}=\frac{\boldsymbol{\omega}_{a, o}-\boldsymbol{\omega}_{a, i}}{\boldsymbol{\omega}_{e q, i}-\boldsymbol{\omega}_{a, i}} \\
\boldsymbol{\omega}_{e q, i}=f\left(T_{s, i}, C_{s, i}\right)
\end{array}
$$

\section{Results and discussion}

Fig. 3 shows the graphs for the heat and mass balance. Most experimental results were situated within $\pm 15 \%$. The heat transfer rate was between about 860 and $1,800 \mathrm{~W}$, and the regeneration rate was between about 10 and $30 \mathrm{~g} / \mathrm{min}$.

Figs. 4 and 5 are pareto charts showing the effects of the six experimental variables on the regeneration rate and regeneration effectiveness. The pareto charts graphically show relative importance of each experimental variables on the results. As shown in Fig. 4, the regeneration rate is significantly influenced by the solution concentration, relative humidity and velocity of regeneration air, and solution mass flow rate at a $90 \%$ confidence level $(\alpha=0.1)$. According to Fig. 5, the regeneration effectiveness is highly influenced by the regeneration air velocity, solution temperature, and dry bulb temperature.

Figs. 6 and 7 are main effects plots showing how the regeneration rate and regeneration effectiveness are affected by changes in experimental variables. As shown in Fig. 6, the regeneration rate was improved as regeneration air velocity or solution mass flow rate increases. But the regeneration rate decreases with increasing the relative humidity and solution concentration. Fig. 7 shows that the regeneration effectiveness decreases with higher regeneration air velocity and solution temperature, and increases with dry bulb temperature.

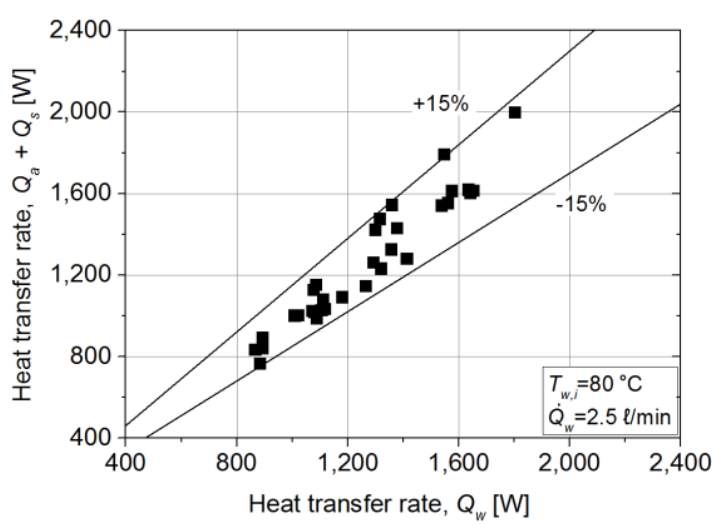

(a) Heat balance.

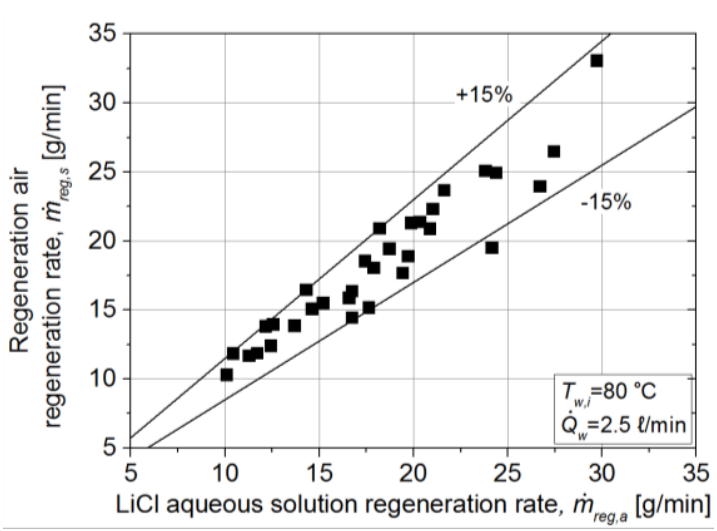

(b) Mass balance.

Fig. 3. Heat and mass balance.

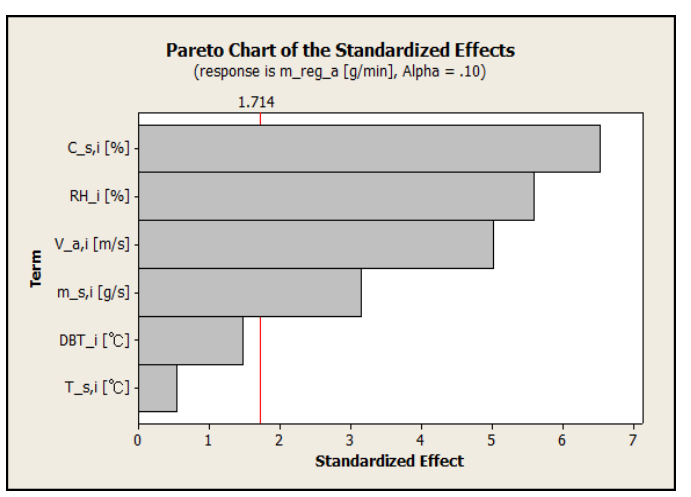

Fig. 4. Pareto chart of regeneration rate, $\dot{m}_{\text {reg,a } a}[\mathrm{~g} / \mathrm{min}]$.

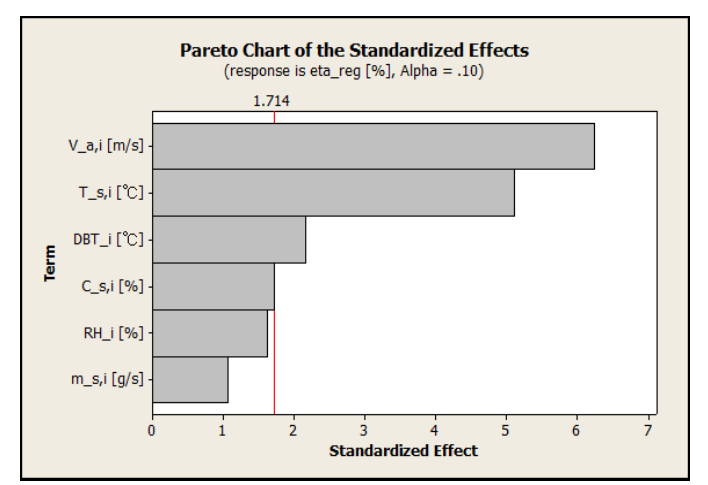

Fig. 5. Pareto chart of regeneration effectiveness, $\boldsymbol{\varepsilon}_{r e g}[\%]$. 


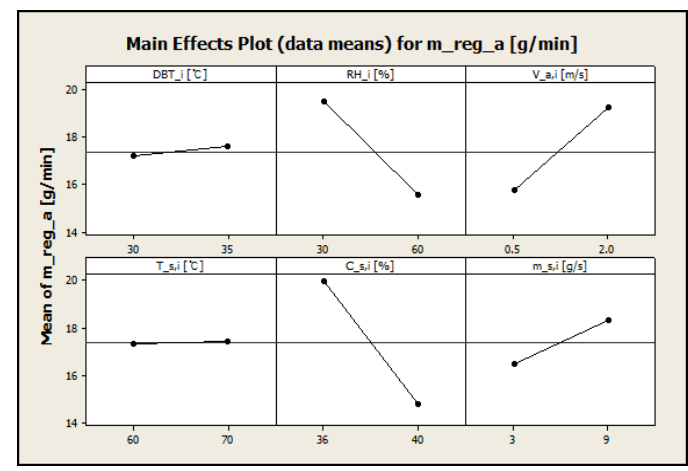

Fig. 6. Main effects plot for regeneration rate, $\dot{m}_{\text {reg,a }}[\mathrm{g} / \mathrm{min}]$.

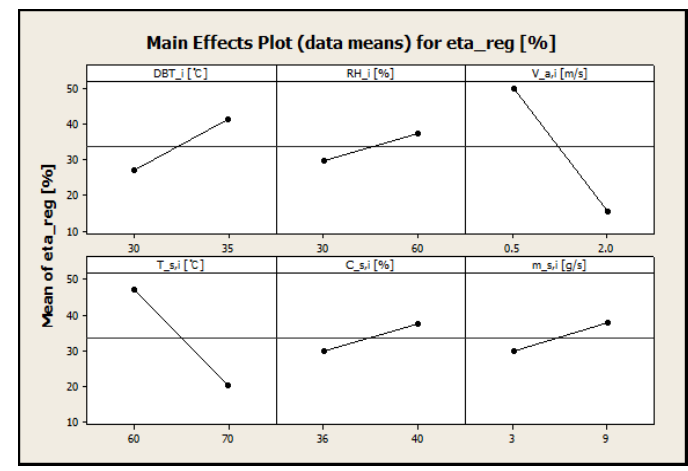

Fig. 7. Main effects plot for regeneration effectiveness, $\boldsymbol{\varepsilon}_{r e g}[\%]$.

Mass transfer in the regenerator occurs due to vapor pressure difference between the air and solution. The vapor pressure of the $\mathrm{LiCl}$ aqueous solution increases at higher temperatures and lower concentrations. Therefore regeneration rate is expected to increase with the solution inlet temperature. However, the experimental results revealed that an increase in solution temperature does not affect the regeneration rate. This is because the role of the heating water in maintaining high temperature of the solution weakens, since the heat transfer rate from the heating water to the solution decreases as the inlet temperature of the solution rises. Fig. 8 shows heat transfer rates of the heating water, regeneration air(sensible heat and latent heat), and $\mathrm{LiCl}$ aqueous solution when the solution inlet temperature varies from 50 to $70^{\circ} \mathrm{C}$.

Figs. 9 to 11 are contour plots showing the relationship between regeneration rate, regeneration effectiveness, and experimental variables. From Fig. 9, we can see that regeneration rate increases as the solution concentration and regeneration air relative humidity decrease. Here, the dry bulb temperature and velocity are $32.5^{\circ} \mathrm{C}$ and $1.25 \mathrm{~m} / \mathrm{s}$, while the solution temperature and mass flow rate are $65^{\circ} \mathrm{C}$ and $6.0 \mathrm{~g} / \mathrm{s}$ respectively.

As shown in Fig. 10, the regeneration rate increases at higher velocity and lower relative humidity of regeneration air. At this point, the dry bulb temperature is $30^{\circ} \mathrm{C}$, while the solution temperature, concentration, and mass flow rate are $60{ }^{\circ} \mathrm{C}, 36 \%$, and $3 \mathrm{~g} / \mathrm{s}$, respectively. The regeneration rate is more affected by the velocity than the relative humidity of regeneration air. According to Fig. 11, regeneration effectiveness was improved when regeneration air velocity and solution temperature declined. Regeneration air velocity had a greater influence on regeneration effectiveness than solution temperature. The dry bulb temperature and relative humidity were $32.5^{\circ} \mathrm{C}$ and $45 \%$, while the solution concentration and mass flow rate were $38 \%$ and $6.0 \mathrm{~g} / \mathrm{s}$ respectively.

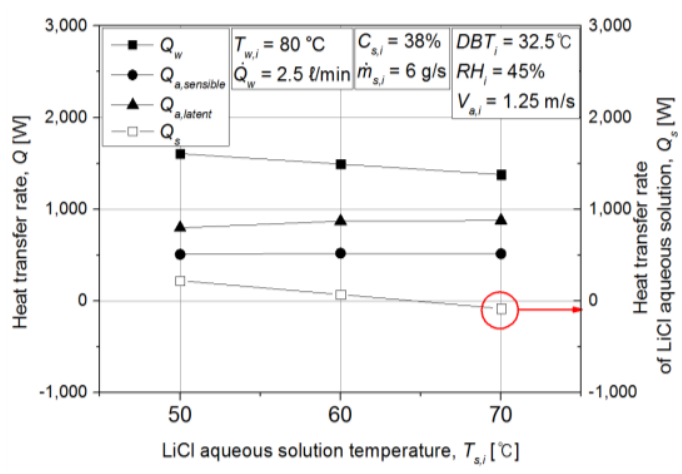

Fig. 8. $\mathrm{LiCl}$ aqueous solution temperature versus heat transfer rate $\left(Q_{w}, Q_{a, \text { sensible }}, Q_{a, \text { latent }}, Q_{s}[\mathrm{~W}]\right)$

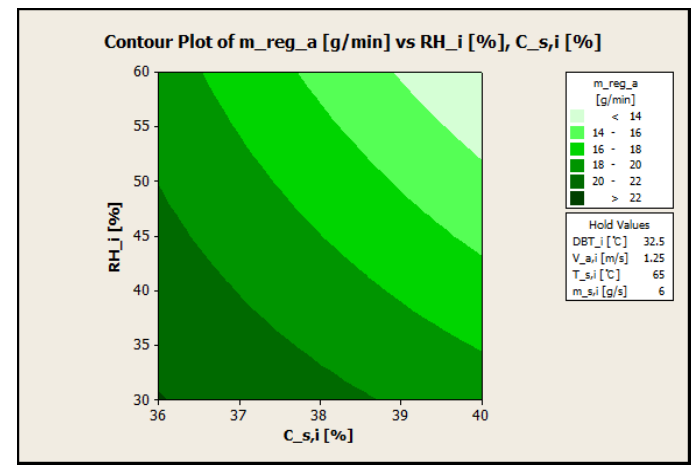

Fig. 9. Contour plot of $\dot{m}_{\text {reg,a }}[\mathrm{g} / \mathrm{min}]$ for $C_{s, i}$ and $R H_{i}$.

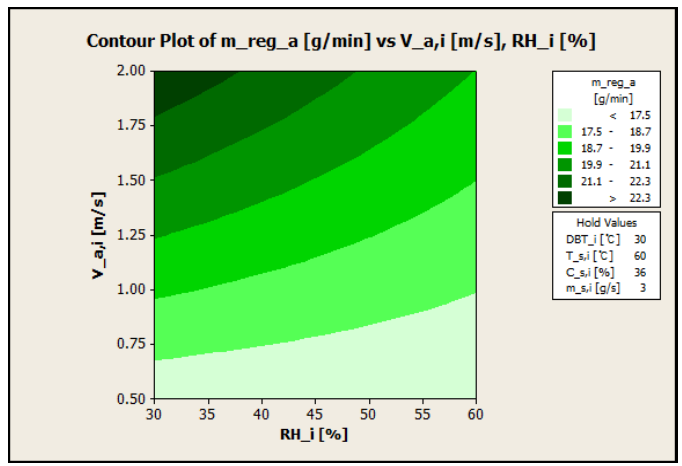

Fig. 10. Contour plot of $\dot{m}_{\text {reg,a }}[\mathrm{g} / \mathrm{min}]$ for $R H_{i}$ and $V_{a, i}$.

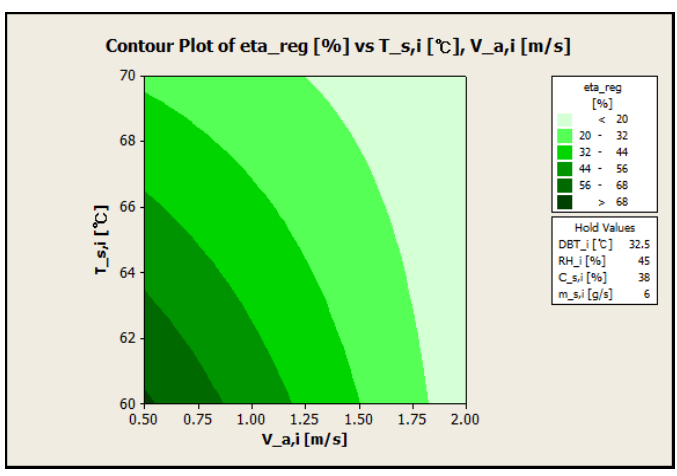

Fig. 11. Contour plot of $\boldsymbol{\varepsilon}_{r e g}$ [\%] for $V_{a, i}$ and $T_{s, i}$. 
The overlaid contour plot, an overlay of contour plots for various response values, can show the ranges of operating conditions satisfying the target values. In this study, regeneration rate and regeneration effectiveness are chosen as the target values. Fig. 12 is an overlaid contour plot showing the effect of the solution concentration and regeneration air relative humidity on the results $\left(\dot{m}_{\text {reg,a }}\right.$, $\left.\boldsymbol{\varepsilon}_{\text {reg }}\right)$. Since the regeneration rate and regeneration effectiveness were larger the better characteristics, the minimum values was set as $20 \mathrm{~g} / \mathrm{min}$ and $25 \%$, respectively. The area satisfying these conditions is given in white in the overlaid contour plot. Table 3 presents an example of the conditions and results laid within the white area of the overlaid contour plot.

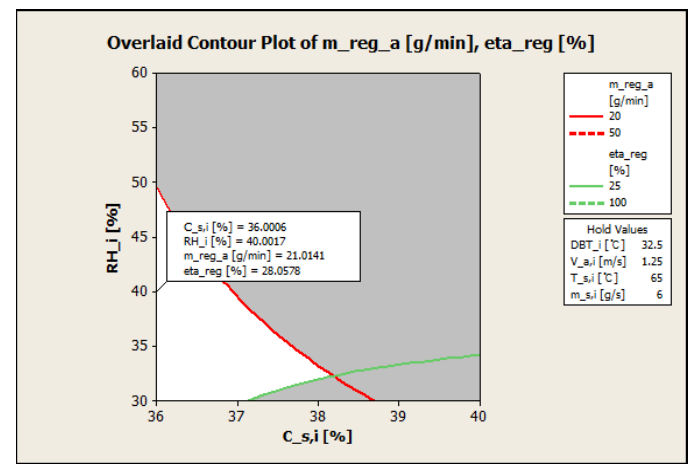

Fig. 12. Overlaid contour plot of regeneration rate $\dot{m}_{\text {reg,a }}[\mathrm{g} / \mathrm{min}]$ and regeneration effectiveness $\boldsymbol{\varepsilon}_{r e g}[\%]$.

Table 3 An example of the conditions and results laid within the white area of overlaid contour plot

\begin{tabular}{|c|c|c|c|c|}
\hline \multirow{4}{|c|}{ Variables } & Unit & Values \\
\hline \multirow{4}{*}{$\begin{array}{c}\text { Experimental } \\
\text { conditions }\end{array}$} & \multirow{3}{*}{ Air } & $D B T_{i}$ & ${ }^{\circ} \mathrm{C}$ & 32.5 \\
\cline { 3 - 5 } & & $R H_{i}$ & $\%$ & 40.0 \\
\cline { 3 - 5 } & & $V_{a, i}$ & $\mathrm{~m} / \mathrm{s}$ & 1.25 \\
\cline { 3 - 5 } & & $T_{s, i}$ & ${ }^{\circ} \mathrm{C}$ & 65.0 \\
\cline { 3 - 5 } & \multirow{2}{*}{$\begin{array}{c}\text { Heating } \\
\text { water }\end{array}$} & $C_{s, i}$ & $\%$ & 36.0 \\
\cline { 3 - 5 } & $\dot{m}_{s, i}$ & $\mathrm{~g} / \mathrm{s}$ & 6.0 \\
\hline \multirow{3}{*}{ Results } & \multicolumn{2}{|c|}{$\begin{array}{c}\text { Regeneration rate } \\
\dot{Q}_{w, i}\end{array}$} & ${ }^{\circ} \mathrm{C}$ & 80.0 \\
\cline { 2 - 5 } & \multicolumn{2}{|c|}{$\begin{array}{c}\text { Regeneration } \\
\text { effectiveness }\end{array}$} & $\mathrm{g} / \mathrm{min}$ & 2.5 \\
\hline
\end{tabular}

\section{Conclusion}

This study conducted experiments and an analysis to study the regeneration performance characteristics of an internally heated regenerator using a $1 / 2$ fractional factorial DOE. The following conclusions were obtained.

(1) Regeneration rate is affected by solution concentration, relative humidity and velocity of regeneration air, and solution mass flow rate in order of significance. Regeneration rate increases as solution concentration and regeneration air relative humidity decrease. And the increase of regeneration air velocity and solution temperature leads to increase of regeneration rate.

(2) Regeneration effectiveness is significantly influenced by regeneration air velocity, solution temperature, and dry bulb temperature. The lower the regeneration air velocity and solution temperature are, the higher the regeneration effectiveness is. And when the dry bulb temperature increases, regeneration effectiveness rises.

(3) Further study is required on experimental variables affecting regeneration performance. The results of this study may serve as a reference in the design of internally heated regenerators for liquid desiccant systems.

\section{Acknowledgement}

This work was supported by the Industrial Strategic technology development program (10042562, Development of heat exchanger type zero carryover liquid dehumidification/regeneration technology) funded by the Ministry of Trade, Industry \& Energy (MI, Korea).

\section{References}

[1] Yin, Y., Zhang, X., Peng, D. and Li, X., "Model validation and case study on internally cooled/heated dehumidifier/ regenerator of liquid desiccant systems", International Journal of Thermal Sciences, 2009, Vol. 48, pp. 1664-1671

[2] Yin, Y., Zhang, X., Wang, G. and Luo, L., "Experimental study on a new internally cooled/heated dehumidifier/ regenerator of liquid desiccant system", International Journal of Refrigeration, 2008, Vol. 31, pp. 857-866.

[3] Zhang, T., Liu, X., Jiang, J., Chang, X. and Jiang, Y., "Experimental analysis of an internally-cooled liquid desiccant dehumidifier", Building and Environment, 2013, Vol. 63, pp. 1-10.

[4] Luo, Y., Yang, H. and Lu, L., "Liquid desiccant dehumidifier: Development of a new performance predication model based on CFD", International Journal of Heat and Mass Transfer, 2014, Vol. 69, pp. 408-416. 